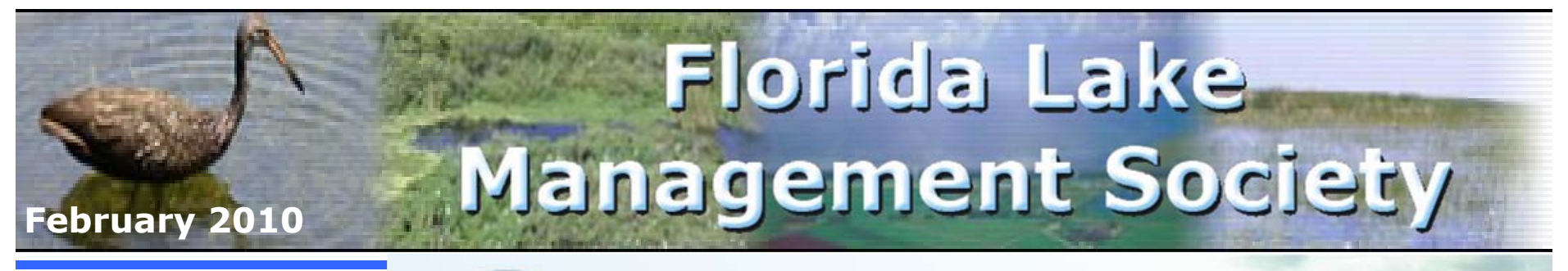

Inside this issue:

21st Annual Conference

Coastal Dune Lakes

Chapter Updates

Love Your Lake

NALMS Update

Shoreline Development Program

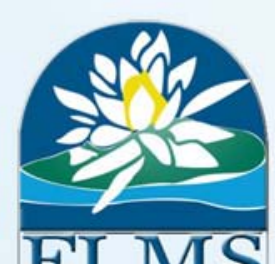

FLMS

LYL - Lake Mobile

\title{
21st Annual Conference
}

FLORIDA LAKE MANAGEMENT SOCIETY

Exploring the Springs Coast
June 14-17, 2010
Crystal River, Florida

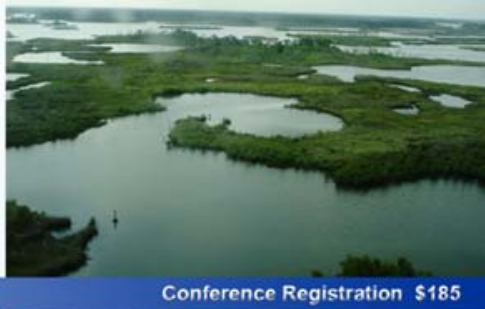

FLMS Membership

Upcoming Conferences

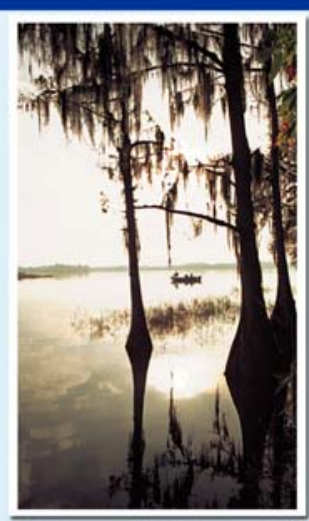

Suggested Special

Sessions for the 2010

Conference include:

Numeric Nutrient Criteria

Development in Florida's Fresh and Estuarine Waters

Tools for Assessing the Link between Nutrients and Lake and Stream Ecology

Regional Water Resource Issues, such as Lake Jesup, Lake

Chapter Representatives

Todd Olson-SE

Sean McGlynn-NW

Ann Shortelle-NE

John Walkinshaw-SW

Sherry Brandt-Williams-Central

Administrative Assistant

Maryann Krisovitch

flmshome@aol.com

Okeechobee, the St. Johns River, King's Bay, etc

\section{SUBMIT YOUR PAPER NOW!}
ABSTRACT DEADLINE IS MARCH 5th, 2010

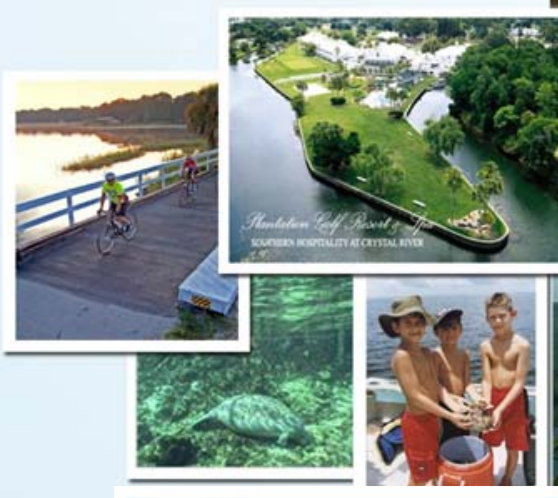

june 12

Weekend in Your Watershed

$$
\begin{gathered}
\text { Dinner Florida Fish Fry } \\
\text { Plant Function and Identification } \\
\text { Reptiles and Amphibians as Indicators } \\
\text { Frog Walk Activity } \\
\text { Kayak Activity }
\end{gathered}
$$

june 14 workshops

$$
\begin{gathered}
\text { Lunch provided with } \\
\text { full-day Workshop registration } \\
\text { Water Quality Monitoring, Data Analysis } \\
\text { and Interpretation } \\
\text { Grant Writing } \\
\text { Lake Vegetation Index Part I (classroom) } \\
\text { Designing a Sediment Removal Project } \\
\text { Lake Vegetation Index Part II } \\
\text { Environmental Mapping with YSI's } \\
\text { EcoMapper AUV }
\end{gathered}
$$

june 16 technical sessions

june 17 technical sessions

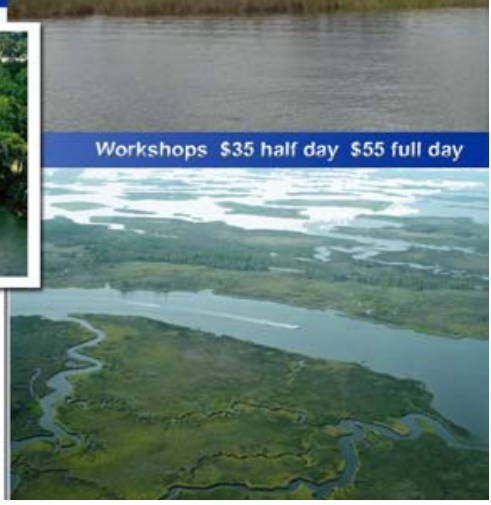

june 13

Weekend in Your Watershed

Breakfast and Lunch Provided Habitat Assessment and Bird ID Water Quality Sampling Techniques Field Sampling Experience Habitat Quality Sampling Techniques Field Sampling Experience Data Management and Web Publication

june 15 technical sessions

General Conference Sessions Breakfast and lunch provided Morning and afternoon breaks Poster Session

FLMS Chapter Meeting Exhibitor's Social
General Conference Sessions Breakfast provided Morning and afternoon breaks Awards Banquet Lunch FLMS Board Meeting

General Conference Sessions
Breakfast provided Breakfast provided

Conference adjourned at Noon River cruise and Dinner Excursion

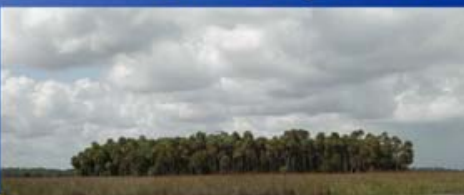




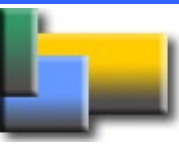

Along the short stretch of coastline from Destin to Panama City Beach in the Florida Panhandle lies a series of globally rare lakes. Known as 'coastal freshwater lagoons' or more simply, 'dune lakes', these tannic water bodies receive surface runoff from the surrounding uplands, in much the same way as many other Florida lakes. However, the dune lakes are unique in their proximity to and connection with the sea; they lie just behind the sand dunes, only a few hundred meters from the saline Gulf of Mexico (Figure 1). Despite the rarity of these lakes, there has been very little scientific study of their functioning.

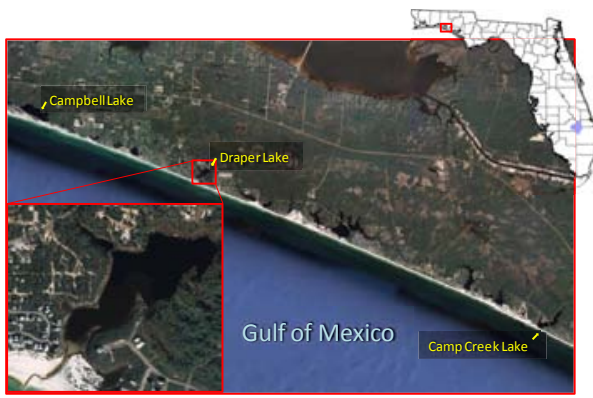

Figure 1. Location map of dune lakes with close view of Draper lake. Source: Google Earth

The most dramatic feature of these lakes is the periodic 'blow-out' that occurs when the water level in a lake builds up high enough to break through the sand separating it from the Gulf and the lake drains rapidly into the ocean. During a blow out episode, a lake may lose as much as a meter of water over several hours (Figure 2) and subsequently may be flooded with salt water from the Gulf. The blow-out frequency varies from lake to lake and the factors controlling the timing, magnitude and duration are not well understood. With support from the CBA, our group at the University of Florida sought to study the blow-out cycles in Campbell, Camp Creek and Draper Lakes. We hypothesized that the timing of blow-outs depends on regional rainfall and tidal periodicity in the Gulf of Mexico.

The population of Walton County, where most of the dune lakes are located grew by more than $30 \%$ from 2000 to 2008, based on US Census estimates. The coastal areas in this part of Florida have been under enormous development pressure. The second objective of this study was to compare water quality, in terms of total nitrogen (TN) and total phosphorus (TP), in the groundwater surrounding three of the lakes and correlate variations in water quality constituents to differences in land use around each lake (ranging from protected forest to residential subdivisions). Our hypothesis was that lakes bordered by developed land had higher TN and TP than lakes abutting natural (forested) land.

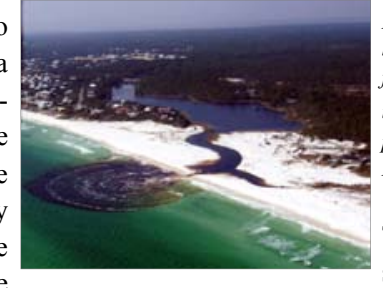

Figure 2. Aerial image of a blowout of dark tannic water from Big Redfish Lake into the Gulf of Mexico (Picture provided by Scott Jackson PhotosFlorida.com).

To test our hypotheses, one open water and three groundwater stations were established at Campbell (CL), Camp Creek (CCL) and Draper Lakes (DL) in Walton County, FL, in May 2007 (Figure 1). Data-logging pressure transducers were installed at each open water station to record the water level, or stage, every hour. The fine timescale of the measurements allowed us to capture daily fluctuations and accurately describe changes in water level during blow-outs, which can often transpire in less than $24 \mathrm{hr}$. More advanced transducers, capable of measuring conductivity, were deployed in Camp Creek and Draper Lakes in May 2008. This report includes data collected through August 2009.

Additionally, approximately once per month, Florida LAKEWATCH (http://lakewatch.ifas.ufl.edu) volunteers collected water samples from the groundwater wells at each lake. The samples were analyzed for TN, TP and color. Surface water samples were not collected as part of this study, because Florida LAKEWATCH already maintains sampling stations in each of these lakes.

\section{Results and Discussion}

\section{Physical characteristics and behavior}

First, we compared water level and salinity between lakes. From these data, we identified four categories of water exchange between the dune lakes and the Gulf of Mexico: Type I, "no exchange;" Type II, blow-out with no saltwater return; Type III, blow-out with saltwater return; and Type IV, "blow in."

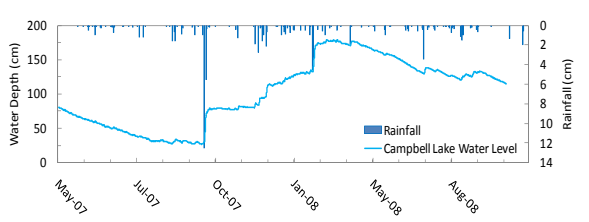

Figure 3. Water level and rainfall at Campbell Lake. Exemplifies Type interaction (no exchange) with the Gulf of Mexico.

Campbell Lake exemplified Type I interaction during our study period; all of the major changes in water level appeared to be associated with rainfall events (Figure 3). It is not surprising that Campbell Lake should have restricted interaction with the Gulf: based on several aerial photos taken between 1999 and 2007, Campbell Lake has no perennial outflow channel across the beach, unlike Camp Creek and Draper Lakes.

In a Type II exchange, when water levels in the lake are sufficiently high to overtop the channel, the fresh lake water flows out without allowing saline Gulf water to flow in. The bottom elevation of the outflow channel must be higher than the elevation of the high tide to prevent the backflow of saltwater. Type II interactions occurred in early April 2009 in both Camp Creek and Draper Lakes (Figure 4) and are likely the most common exchanges for lakes with outflows.

When built up lake water forces open a channel to the Gulf with a bottom elevation low enough to allow salt water to flow in, a Type III blow-out occurs. These episodes are visible on both the water level and the conductivity records. This exchange type was comparatively rare during the study period, occurring only once (17 July 2008 in Draper Lake) over the period for which salinity data were available (May 2008 to August 2009). When the blow-out occurred, the lake lost about a meter ( $3 \mathrm{ft}$ ) of water in only 4 hours. For the 5 days that the channel was open, salt water flowed in and out of the lake with each tidal cycle, leaving the transducer exposed during each low tide (Figure 5). By the time the channel closed, the salinity in the lake had more than doubled.

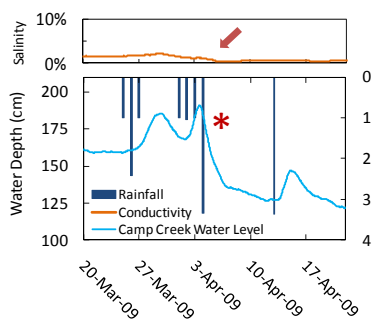

Figure 4. Type II exchange in Camp Creek Lake. Starting on April $2^{\text {nd }}$ (asterisk), the water level fell about $75 \mathrm{~cm}(2.5 \mathrm{ft})$ over about 10 days. Note that the salinity did not increase during the outfall event, indicating no inflow of Gulf water.

The last class of exchange, Type IV, is a "blow-in" that occurs when saline Gulf water enters a lake without an outflow of freshwater. It requires an extreme event (like a hurricane) to force Gulf water into an "unopened" lake, so this type of water flow is probably unusual. We were fortunate to have transducers installed during the 2008 hurricane season and we captured the impacts of Hurricanes Gustav and Ike. Both cyclones produced storm surges that forced saltwater over the beach and into Camp Creek Lake (Figure 6). The salinity receded while the stage did not because saltwater is denser than fresh lake water; the water from the Gulf settled to the bottom of the lake after the storms had passed.

These exchanges likely serve at least two functions for the dune lakes. First, Type II and Type III blow outs augment the turnover of the lake water, maintaining a cycle of purging and refilling that prevents the stagnation of the water that might otherwise have no outflow except infiltration or evaporation. Second, Type III and Type IV exchanges introduce significant amounts of saltwater to these lakes that might otherwise be strictly freshwater. This may change the composition of plant and animal species that can inhabit the dune lakes. 
The timing and frequency of these exchanges are not strictly controlled by rainfall and lake water level. The morphology (size and shape) of the outflow channel appears to play a large role in determining when a lake is "ready" to blow out. For example, the water level record indicates three distinct Type II and Type III blow-outs of Draper Lake between July 2008 and April 2009 (not shown). These blow-outs initiated at three different water levels: 100,80 and 200 $\mathrm{cm}$, respectively, implying that the outflow channel reformed to a different elevation following each event.

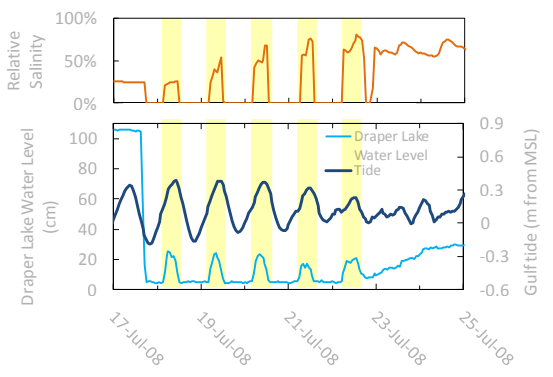

Figure 5. Type III exchange in Draper Lake. The lake water level and conductivity peak with each subsequent high tide after the channel opening (July 17th). The transducer was exposed during each low tide.

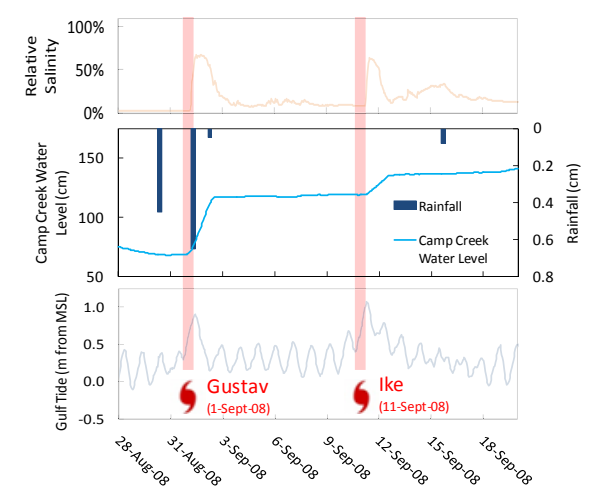

Figure 6. Type IV interactions, or "blow-ins" in Camp Creek Lake. The storm surge from Hurricanes Gustav and Ike appear in the tide record and cause rapid increases in the lake stage and salinity.

\section{Water quality: Phosphorus, nitrogen and clarity}

We examined TP and TN in the groundwater adjacent to the three study lakes as a proxy for water quality entering the lakes from the surrounding land. The median groundwater TP concentrations varied from 4 to $40 \mu \mathrm{g} / \mathrm{L}$ and the median $\mathrm{TN}$ concentrations ranged from 227 to $1104 \mu \mathrm{g} / \mathrm{L}$ across the three lakes (Figure 7). These values span from oligotrophic (low potential for primary productivity, or plant growth) to eutrophic (high potential for primary productivity) within the classification scheme developed by Nürnburg (1996). As a point of reference, the famously eutrohpic Lake Apopka and Lake Okeechobee have TP of 200 and $191 \mu \mathrm{g} / \mathrm{L}$, respectively, and TN of 500 and $1590 \mu \mathrm{g} / \mathrm{L}$, respectively (Bachmann et al., 2001 and Zhang et al., 2009). In these three dune lakes, the eutrophication potential (based strictly upon TN and TP) is generally less than these two larger, more polluted lakes. Also, the dark color of the water (Figure 1 inset) reduces light penetration and lends the dune lakes some protection from algae blooms, which are a common symptom of eutrophy. This is corroborated by Florida LAKEWATCH chlorophyll data (a measure of algae production) that did not indicate excessive algae growth in any of our three lakes.

Our major hypothesis regarding water quality was that lakes abutting land subject to human activities (termed "developed" here; Camp Creek and Draper Lakes) would have higher levels of TP and TN than lakes surrounded by natural areas ("undeveloped", Campbell Lake). Aerial photos were used to determine the land use surrounding each lake (and around each station within each lake) to gauge the connection between land use and water quality. Based on the average TP and TN concentrations presented in Figure 7 , there was no clear distinction between developed and undeveloped lakes.

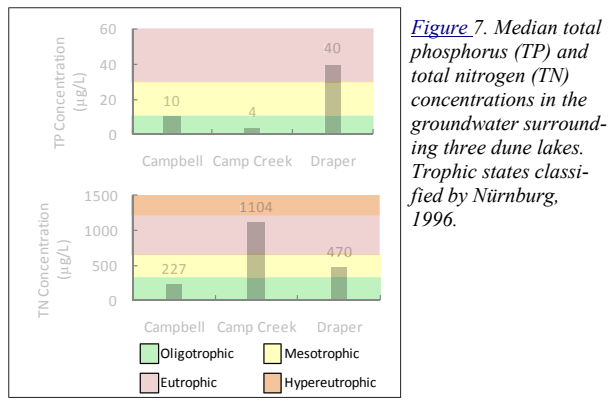

The developed lakes have portions of shoreline that are still forested, so we suspected that the water quality impacts of land development would be most apparent at the groundwater stations located closest to residential areas. At Campbell Lake, all three stations were surrounded by protected woodlands within Topsail State Park. As expected, TN and TP did not vary significantly from station to station (Figure 8 ). In October 2008, the sample from Campbell station 4 returned unusually high TP $(239 \mu \mathrm{g} / \mathrm{L})$ and TN $(3140$ $\mu \mathrm{g} / \mathrm{L})$. Neither the rainfall nor the prescribed fire record maintained by Topsail State Park indicated any unusual events immediately preceding the collection of the suspect sample. Possibly, however, one of the three named storms (Fay, Gustav and Ike) that passed near Walton County in August and September 2008 caused the elevated TP and TN. Figure 7 reports the average TP and TN both with (full extent of green column) and without (black hash mark) that sample included.

At Draper Lake, all three stations were positioned along the northwest shore. Draper station 2 was surrounded by a residential community. The land around Draper stations 3 and 4 had been plotted and partially cleared for future neighborhoods. The majority of the southwest shore was forested. For both TP and TN, Station 4 had the highest average concentrations and Station 3 had the lowest (Figure 9). This does not support our hypothesis that residential development should contribute excess TP and TN to the dune lakes, but the conclusion is tenuous since we did not have any stations on the forested southwest shore.

Only at Camp Creek Lake was the water quality correlated to land use. Station 2, the only station near residential property, had exceptionally high $\mathrm{TN}$, compared to the other stations at that lake (Figure 10). From this, it is tempting to conclude that the residential community on the southeast shore of Camp Creek Lake contributed a disproportionate fraction of the cumulative TN load to that lake. However, because water quality was not well predicted by land use around Campbell and Draper Lakes, it is difficult to be sure whether the elevated TN at station 2 of Camp Creek Lake was actually a result of land use, or if some unseen factor influenced the results.

While development of the surrounding land may contribute increased loads of nitrogen and phosphorus to the dune lakes, as exemplified by our findings at Camp Creek Lake, it is emphasized that more work is needed to understand the direct biological impacts of these nutrient loads in the dune lakes. While the lakes are afforded some insulation from eutrophy by their tannic color and their exchanges with the Gulf of Mexico only the vigilant eye and low-impact practices by local homeowners will protect these priceless lakes forever.

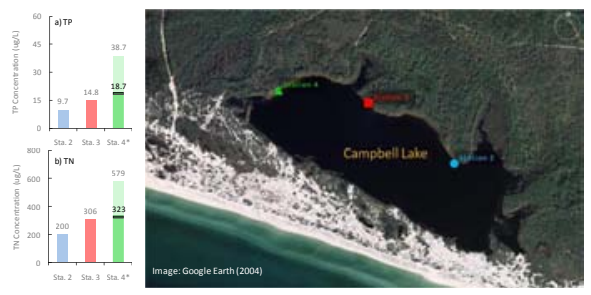

Figure 8. Locations and average total phosphorus (TP) and total nitrogen (TN) concentrations of stations at Campbell Lake. TP and TN averages at station 4 are shown with (top of the green bar) and without (black hash mark) the October 2008 sample, which had unusually high levels of both constituents.

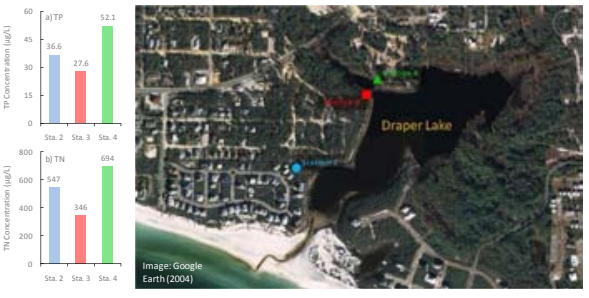

Figure 9. Locations and average total phosphorus (TP) and total nitrogen (TN) concentrations of stations at Draper Lake.

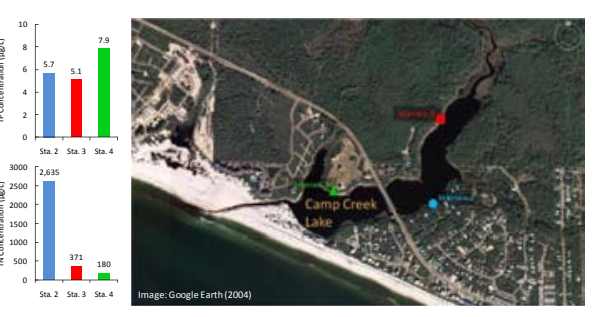

Figure 10. Locations and average total phosphorus (TP) and total nitrogen (TN) concentrations of stations at Camp Creek Lake.

\section{References}

Bachmann, R.W., M.V. Hoyer, and D.E. Canfield, Jr. 2001. Evaluation of recent limnological changes at Lake Apopka. Hydrobiologia 448:19-26.

Nürnberg, G. K., 1996. Trophic state of clear and colored, soft- and hardwater lakes with special consideration of nutrients, anoxia, phytoplankton and fish. Lake Reserv. Manage. 12: 432-447. 


\section{Central Chapter Update}

The next Central Florida Lake Management Society (CFLMS) chapter meeting will be held on March 3 $3^{\text {td }}$ at Volusia County's Lyonia Environmental Center (LEC) in Deltona. Presenters from Stetson University, Volusia County, the City of South Daytona and the University of South Florida will be discussing such topics as fish and invertebrate research, salt marsh restoration, stormwater treatment and flood control projects, surface water monitoring, and a regional Water Atlas concept. In addition, attendees will hear from LEC staff and have the opportunity to explore the facility and the adjacent Lyonia Preserve during the meeting.

For more information about this event, contact Joseph Faella at ifaella@dmces.com

To learn about the Lyonia Environmental Center and the Lyonia Preserve, go to http://lyoniapreserve.com/lec.htm.

The Central Chapter has quarterly meetings throughout Central Florida. For more information or to become involved with the Central Chapter, please contact Ron Novy at ron.novy@ocfl.net
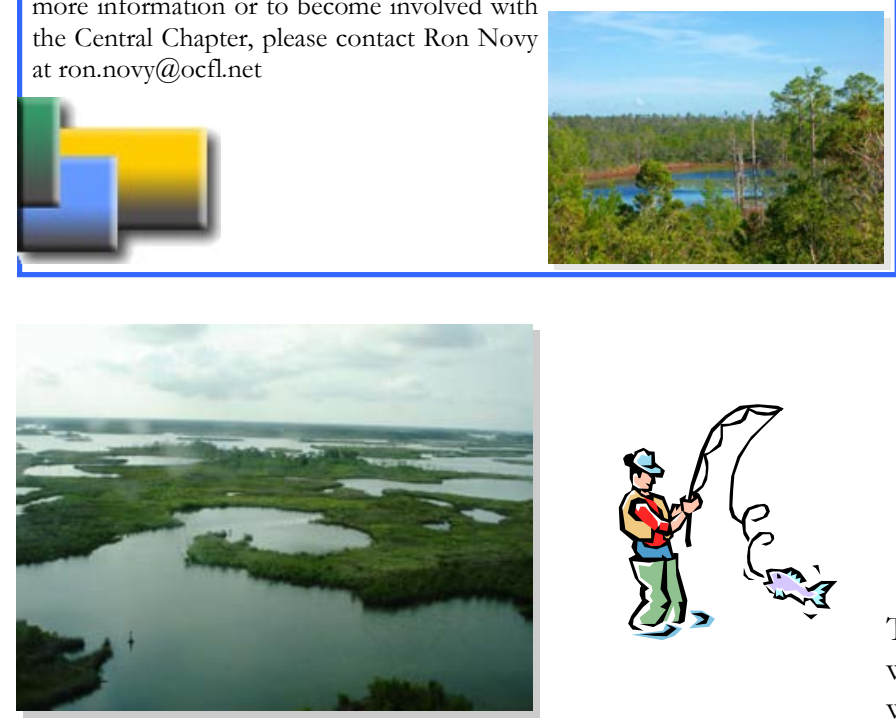

Aerial of Barrier Islands near Homosassa River

\section{Weekend in My Watershed \\ Saturday and Sunday, June 12-13}

This event is targeted toward citizens, teachers and anyone else interested in learning about their watershed. The weekend events will be held at the Plantation Inn as well as out on the water, so bring your kayak! Naturalists and scientists from the Southwest Florida Water Management District, USF, FDEP, Hillsborough County and Pinellas County will lead the numerous planned workshops and field activities. Formal training and demonstrations will be held at the Plantation Inn conference facility. Other demonstrations and nature walks will take place on the grounds of the Plantation Inn and the waters of Kings Bay.

The cost is $\$ 75$ per person for the weekend event. There are a limited number of $\$ 25$ scholarships available on a first come, first served basis. Information for reserving your room at the Plantation Inn at the special rate of $\$ 109$ per night is located on the brochure. When you call to register go to flms.net

\section{Southwest Chapter Update}

The Southwest Chapter of the Florida Lakes Management Society co-hosted a luncheon with the Tampa Bay Association of Environmental Professionals on January 20, 2010. The meeting was held at the Feather Sound Country Club in Pinellas County and attended by 45 people.

The featured presenter was Dr. Daniel Smith, Ph.D., PE,

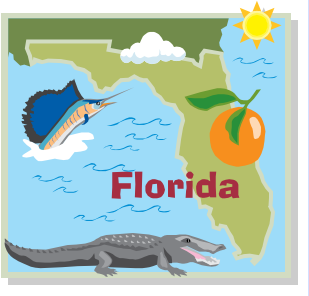
DEE - GPI Southeast, Inc. The topic was a Baffle Box Effectiveness Monitoring Project. GPI Southeast, Inc. (GPI-SE) was engaged by Sarasota County using funding from the Florida Department of Environmental Protection (FDEP) to determine the pollutant removal effectiveness of Type 1 and Type 2 baffle box BMPs. Type 2 baffle boxes have horizontal sieve screens above the pipe inverts so that floating organic matter and suspended sediments can be trapped above the water filled vaults. The design hypothesis for the screen is that organic matter trapped above the water will not leach nutrients into the water filled vault below. Type 1 baffle boxes do not have horizontal sieve screens, rather, they have swinging vertical screens that are ineffective for capturing debris.

The Southwest chapter will be hosting a tour of CF Industries mining operations and reclamation efforts this spring. The tour will include visiting several reclamation sites. CF Industries environmental scientists will discuss the reclamation process and discuss their efforts to shorten the reclamation period from about thirty years down to about 20 years. In addition, the tour will include a look at a recreated wetland/settling pond used to filter runoff from mining areas. CF Industries is working with the Southwest Florida Water Management District on the research and pilot project. It is hoped that this water could be stored in old mining pits and used for agricultural irrigation.

For more information or to become involved with the Southwest Chapter, please contact John Walkinshaw at wrc.fl@verizon.net

\section{Message From the President}

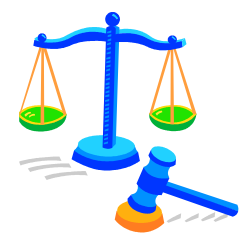

The year is flying by and I have been enjoying my post as president of this wonderful organization. It can be very difficult moving an organization forward, especially in today's economic climate, but with the support and commitment of the FLMS Board we have made several improvements including a new web site which will include on-line conference registration and payment and a streamlined grant application process for the Love Your Lake and Shoreline Grant programs. Additionally, in conjunction with the FLMS annual conference at the Plantation Inn in Crystal River (June 14-17, 2010), the Society will host $A$ Weekend in $M y$ Watershed event June 12-13, 2010. For more information on this event go to www.flms.net and check out volunteer activities under the annual conference header.

Speaking of the annual conference, Jim Griffin and John Walkinshaw have been working diligently on coordinating conference activities and Shannon Wetzel has scheduled several technical workshops that are sure to fill up quick so register early. We have an exciting program planned including presentations and round table discussions on numeric nutrient criteria and site specific alternative criteria for Florida's lakes; springs and spring runs; biological indicators; and more. Check out the call for papers for all the details on platform topics, hotel registration, and activities and remember short abstracts are due March 5, 2010 (hint, hint).

Hope to see you in Crystal River,

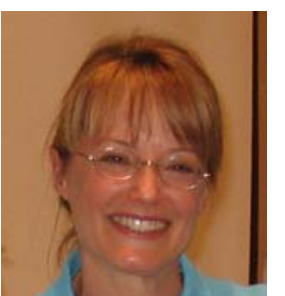




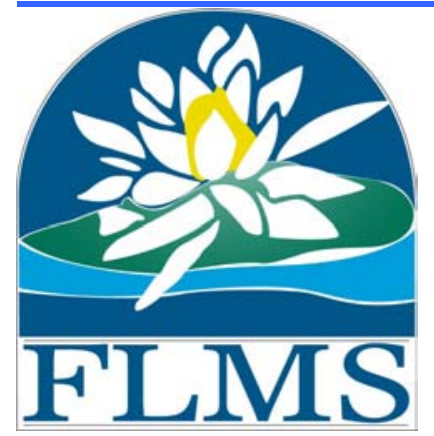

Lave Trour Lake

Deadline

Marek 1. 2010

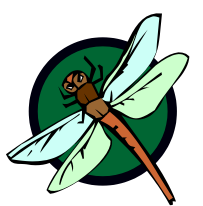

\section{Love Your Lake Cost Share Program}

FLMS has created a cost-share program that funds lake, pond and shoreline projects demonstrating management techniques that help protect, preserve and restore Florida's aquatic resources. Each year FLMS solicits grant proposals describing successful management projects. FLMS will provide matching funds for expenses incurred by the selected applicant. Expenditures may be in the form of labor or monetary contributions utilized in the program. Proposals are reviewed by a selection committee based on the following criteria:
Monetary or labor match programs encouraging community involvement are strongly recommended.

Location - project must be accessible to the public (may include large communities or neighborhoods-dependent on accessibility).

Signage - educational component explaining project.

Water quality enhancements examples include xeriscaping, environmental berm and swale, and other innovative erosion control techniques.

"Love Your Lake" project proposals must be submitted by March 1, 2010. Projects must be completed by May 1, 2010. If you have any questions, please e-mail Sherry Brandt Williams at

Sbrandt-williams@sjirwmd.com.

For more details about the "Love Your Lake" cost-share program, please visit www.flms.net.

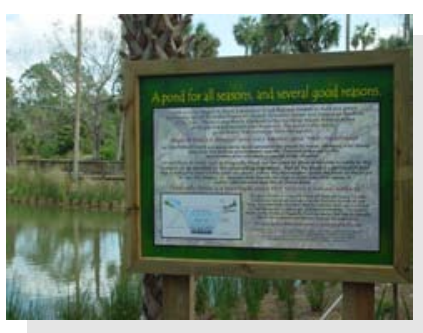

Central Florida Zoo LYL Project

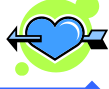

\section{Editor's Corner}

There are all kinds of exciting things happening with FLMS and lake management throughout the state! These include "Love Your Lakes" projects, new proposed statewide nutrient criteria and revised stormwater rules, TMDLs and BMAPs.

I encourage each of you to get involved with your local FLMS chapter and attend the annual meeting to keep up to date on the many lake management issues evolving. Don't forget to spread the word about our new free student membership to all of the future limnologists out there.

The goal of the FLMS newsletter is to provide a method to inform all FLMS members of the activities and efforts throughout all of Florida. Please let me know of any other upcoming events, conferences or articles that you would like included in the newsletter.

Please send comments and information to:

Shannon Carter Wetzel

swetzel@seminolecountyfl.gov

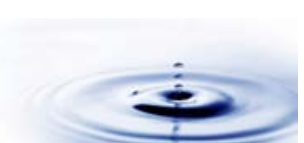

FLMS has launched their new website at flms.net

Many more features, including electronic registration, archives, forms, etc

\section{NALMS Wants You}

Provided by Ann Shortelle, Region IV Director

NALMS enters the new decade with renewed emphasis on representing our members on the national and international stage on important water-related issues we are facing. The NALMS annual conference, professional journal (Lake and Reservoir Management) and Lakeline magazine provides valuable educational material and forums for information exchange. Check out the new member benefit to receive an additional electronic journal (in addition to our NALMS publications) for a year from Taylor and Francis, our publisher, with membership renewal. Check out the new NALMS student section (Dana Bigham, UF, is the USA student contact).

Florida NALMS members are an impressive percentage of the Region 4 NALMS membership, but are YOU a member? Join today! We need every voice! As the NALMS Region 4 Director and a FLMS member, I'd like to challenge each FLMS member who is also a NALMS member to recruit one additional FLMS member to join NALMS. Send me (abshortelle@mactec.com) your successful recruit information, and you'll be entered in a drawing for a FABULOUS (?) prize at the FLMS conference. Join us also at the upcoming NALMS Southeastern Lake Management Conference - Managing Extremes: Watersheds and Climate Disruptions, May 4-7 in Winston-Salem, NC, and the NALMS Annual Symposium in Oklahoma in November.

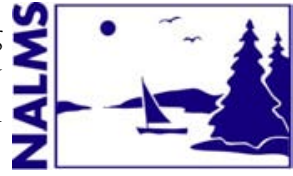




\section{Shoreline Development Funding Program}

\section{Did you know?}

The Florida Lake Management Society (FLMS) sponsors an annual Shoreline Development Funding Program. The FLMS will provide specific grants through local sponsors such as governments and environmental organizations to distribute to shoreline homeowners for enhancement projects that combine a beneficial, native, aquatic plant habitat with some simple stormwater treatment techniques. Each homeowner may receive up to $\$ 200$ for projects approved by the local sponsor and FLMS.

\section{Local Sponsors}

FLMS offers this program to local governments and environmental organizations for distribution to selected shoreline homeowners. Each organization can apply for up to $\$ 1,000$ to distribute. This program can be integrated into an existing water quality effort such as Adopt-A-Shore, Adopt-A-Pond, or other volunteer-oriented efforts. The sponsoring agency will administer the grants through selection of participants and verification of project completion. FLMS will approve each grant.

Grant selection process

Each homeowner must submit an application that includes: -name, address, and contact number or email address -pictures of the shoreline before any work is done. (if available) -explanation on one sheet of paper of the proposed improvements to the shoreline area and why this will be beneficial to the surrounding environment.
Upon completion of the project

Each homeowner or local entity must submit: -a brief description of the completed projected -receipts for any purchases -pictures of the completed project

\section{Not sure where to start?}

The FLMS Shoreline Funding Program is administered by a local entity. The sponsoring agency can help you decide which aquatic plants are beneficial to the environment, what permits may be needed and who to contact, and how to construct simple stormwater treatment areas, such as a berm and swale system.

Please contact Sherry Brandt Williams at Sbrandt-williams@sjrwmd.com.

$\underline{\text { Send individual proposals to: }}$

FLMS

PO Box 950701

Lake Mary, FL 32795-0701
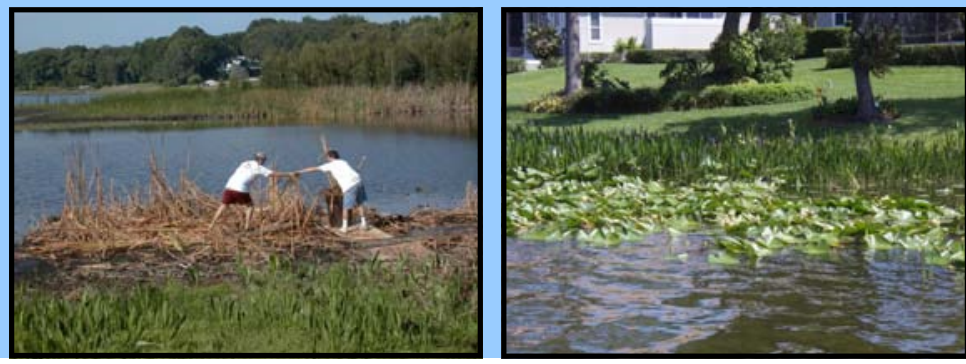

\section{LYL Award Recipient Rosenwald School Lake Mobile \\ Seminole County}

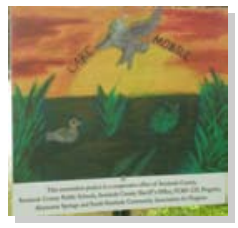

Rosenwald School serves students identified as needing Severely Emotionally Disabled (SED) service supports from 8th grade to age 22 within the public Seminole County School System. Many of these students have experienced failure on a regular school campus because of severe problems in individual behavior and lack of social interaction skills. The objective of this project was to enhance the shoreline by removing nuisance exotic species and replanting with native aquatic plants and incorporate into the school curriculum as an interactive educational opportunity for the students attending Rosenwald.

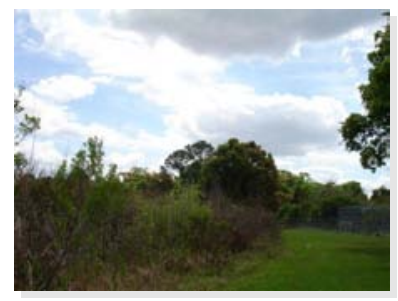
Lake Mobile, a 24 lily, duck acre waterbody, is cord grass, located in Altamonte rush and
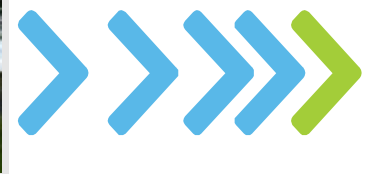

\section{.}

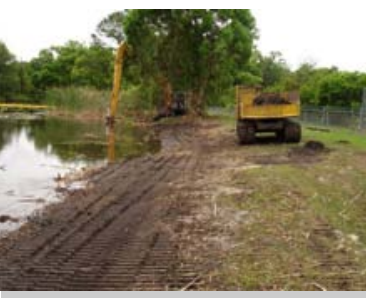

Springs with a significant shoreline existing within beneficial native aquatic plants. Native shoreline plantschool property. This waterbody is comprised of com- ing was designed to enhance water quality through mercial, industrial and residential community lakefront nutrient removal reducing nuisance detrital biomass, watershed, an impaired watershed with boundaries life habitat in which students can monitor over time the Act. This Act was signed into law in 2004 for the overall lake water quality improvements. Additionally,

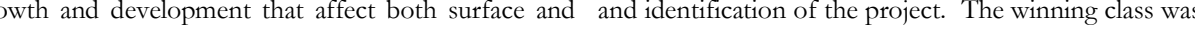
groundwater resources. This shoreline enhancement awarded with their own sign being professionally inactivities. Lake Mobile. Plants used for re-vegetation include: canna, maidencane, pickerelweed, spatterdock, water potato
bull bull other are displayed on site. County biologists continue to incorporate a hands on learning environment for Rosenwald students in which outdoor educational activities are incorporated with the restoration site. Among many activities, students identify macroinvertebrates, birds, aquatic plants within the restoration site documenting biotic changes within their project.
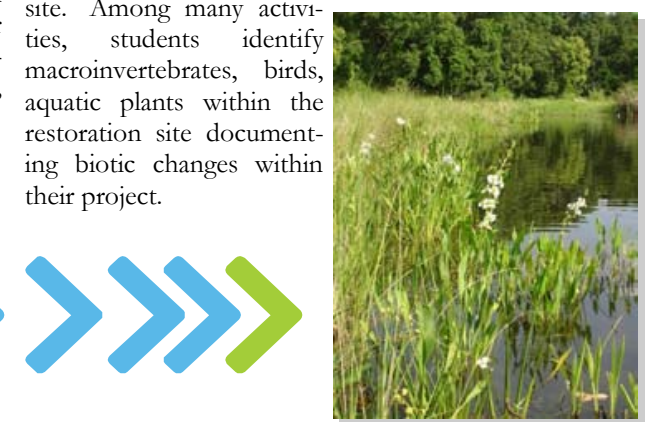


\section{Florida Lake Management Society}

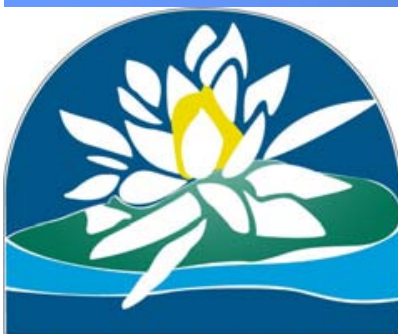

P.O. Box 950701

Lake Mary, FL 32795-0701

E-mail:flmshome@aol.com
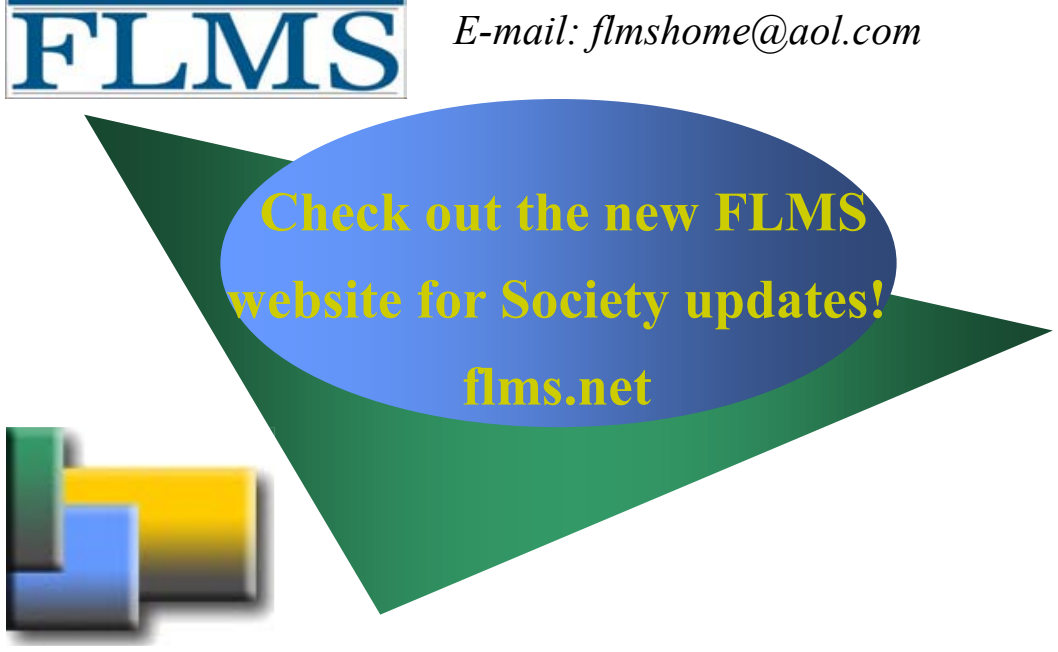

\section{Join}

\section{FLMS Now!}

Annual Dues (Includes Newsletter)

Student / Volunteer FREE

Individual \$25

Non-Profit Organization \$35

Business/Corporate $\$ 65$

Contributor $\$ 100$

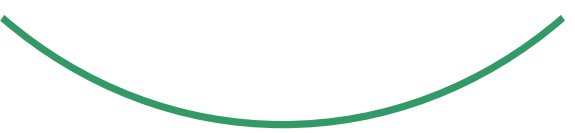

\section{Upcoming Conferences And Workshops}

2010 AWRA Spring Specialty Conference

Geographic Informatin systems (GIS) and Water Resources VI

March 29-31, 2010

Rosen Shingle Creek Hotel, Orlando

NALMS 19th Annual Southeastern Lakes Management Conference Managing Extremes: Watersheds \& Climate Disruption

May 5-7, 2010

Winston-Salem, North Carolina

Joint ASLO and NABS Summer Meeting

Aquatic Sciences: Global Changes from the Center to the Edge

June 6-11, 2010

Santa Fe, New Mexico

Florida Stormwater Association 2010 Annual Conference

Keeping Pace with New Water Quality Strategies

June 9-11, 2010

Sanibel Harbour Marriott Resort \& Spa

FLERA 2010 Annual Conference

Leveraging the Green Revolution

July 28-30, 2010

Hyatt Regency, Sarasota
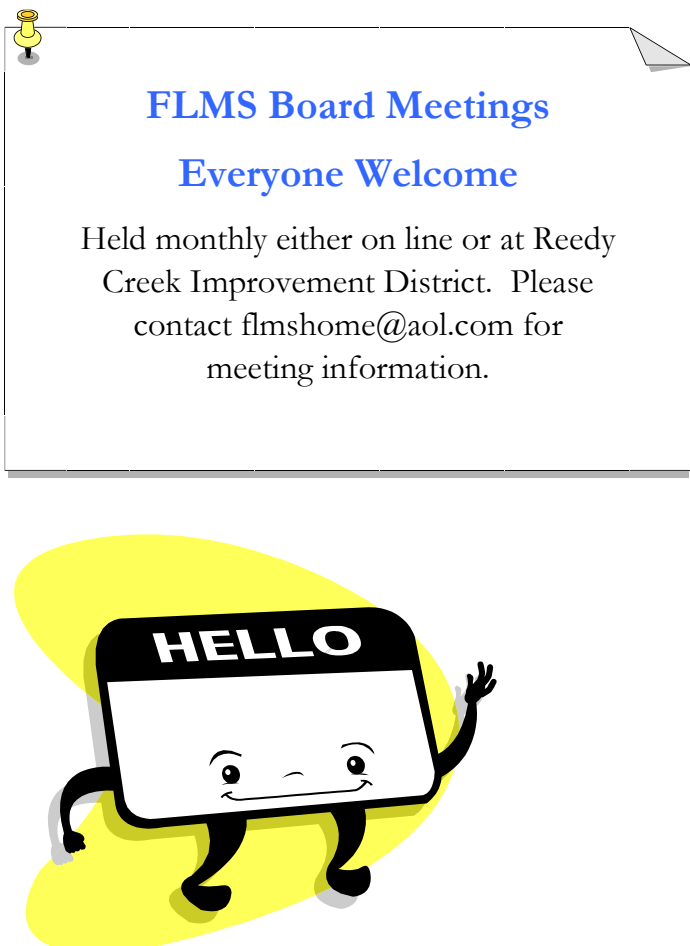

\section{FLMS is a 501c (3) Tax Exempt Organization - Donations are Tax Deductible}

The Florida Lake Management Society (FLMS) is a 501(c)(3) Nonprofit Organization. A copy of the official registration and financial information may be obtained from the Division of Consumer Services by calling toll-free within the State, 1-800-435-7352. Registration does not imply endorsement, approval, or recommendation by the State. FLMS receives $100 \%$ of each charitable contribution. CH 3578. 

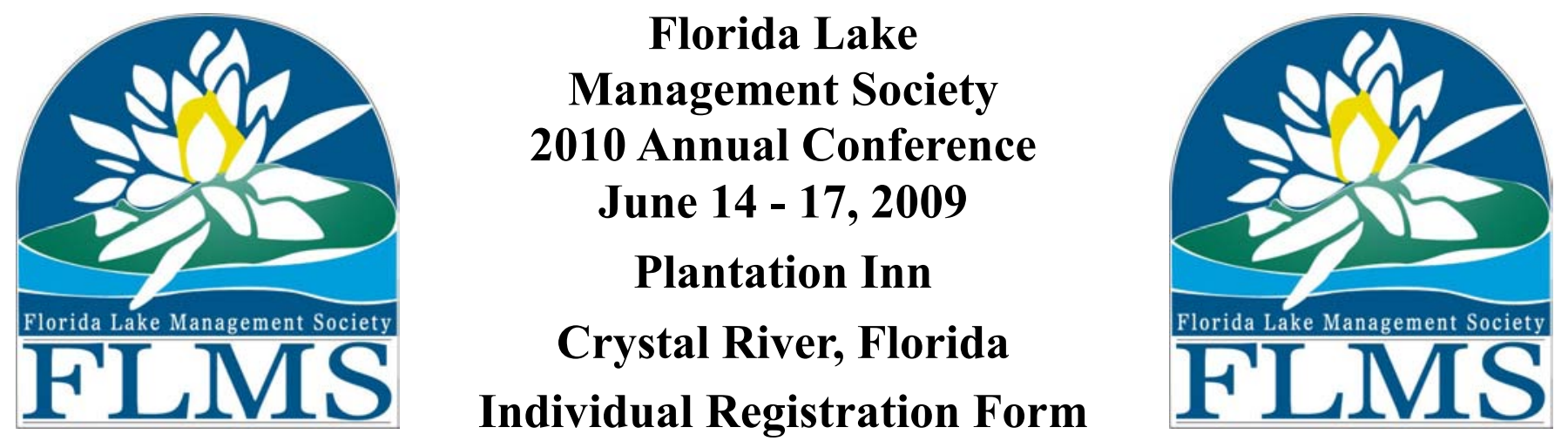

Name:

(As you would like it to appear on your name badge and member directory)

Email:

Business or Agency Affiliation:

Address:

City: State: Zip: FL County:

Phone: Home: Work: Fax:

3 Day Registration - \$185; after May 15 - \$225

Student - \$135

Spouse - $\$ 135$

Daily Registration (Per Day) - \$75.00 (T,W)

Workshops (June 4) 1/2 day - \$35; full day - \$55

Select Workshop(s) \#: Morning \# (1-4) and/or Afternoon \# (5-6)

(Registration in morning workshop \#2 is required for afternoon workshop \#5)

\section{Additional Guest Banquet Ticket - \$25}

I request $\mathrm{ADA}$ assistance.

Total to FLMS

\footnotetext{
Please make checks payable to: The Florida Lake Management Society and return to: Florida Lake Management Society, P.O. Box 950701, Lake Mary, Fl., 32795-0701. Remittance by credit card is also available online by PayPal or by including credit card information listed at the bottom of this form. Fax form to (407) 884-5149, no cover sheet needed. This is a private, secure fax. For registration questions, contact Maryann Krisovitch at (352) 434-5025. Three-day registrations include daily breakfast and breaks on June 15, 16, and 17, a banquet luncheon on June 16 and evening reception on June 15. Full day workshop registrations include lunch on the $14^{\text {th. }}$. If ADA assistance is required, please indicate your needs on this registration form. Hotel rooms at a reduced conference rate of $\$ 109.00$ ( $\$ 70$ government rate) per night are available at the Plantation Inn. Hotel reservations must be made prior to May 6, 2010 to secure a room at the conference rate, subject to block availability. To make your room reservation, visit the FLMS website at http://flms.net and click on the Plantation Inn link on the main page. To learn more about the Plantation Inn visit their web site at (http://www.plantationgolfandspa.com/).

For more conference information visit the FLMS web site at http://flms.net or contact the Conference Co-Chair, Jim Griffin at griffin@arch.usf.edu or John Walkinshaw at wrc.fl@,verizon.net.
}

\section{Credit Card Info}

Name on card Vis a or MasterCard?

Card number Expiration date

Billing address for card 